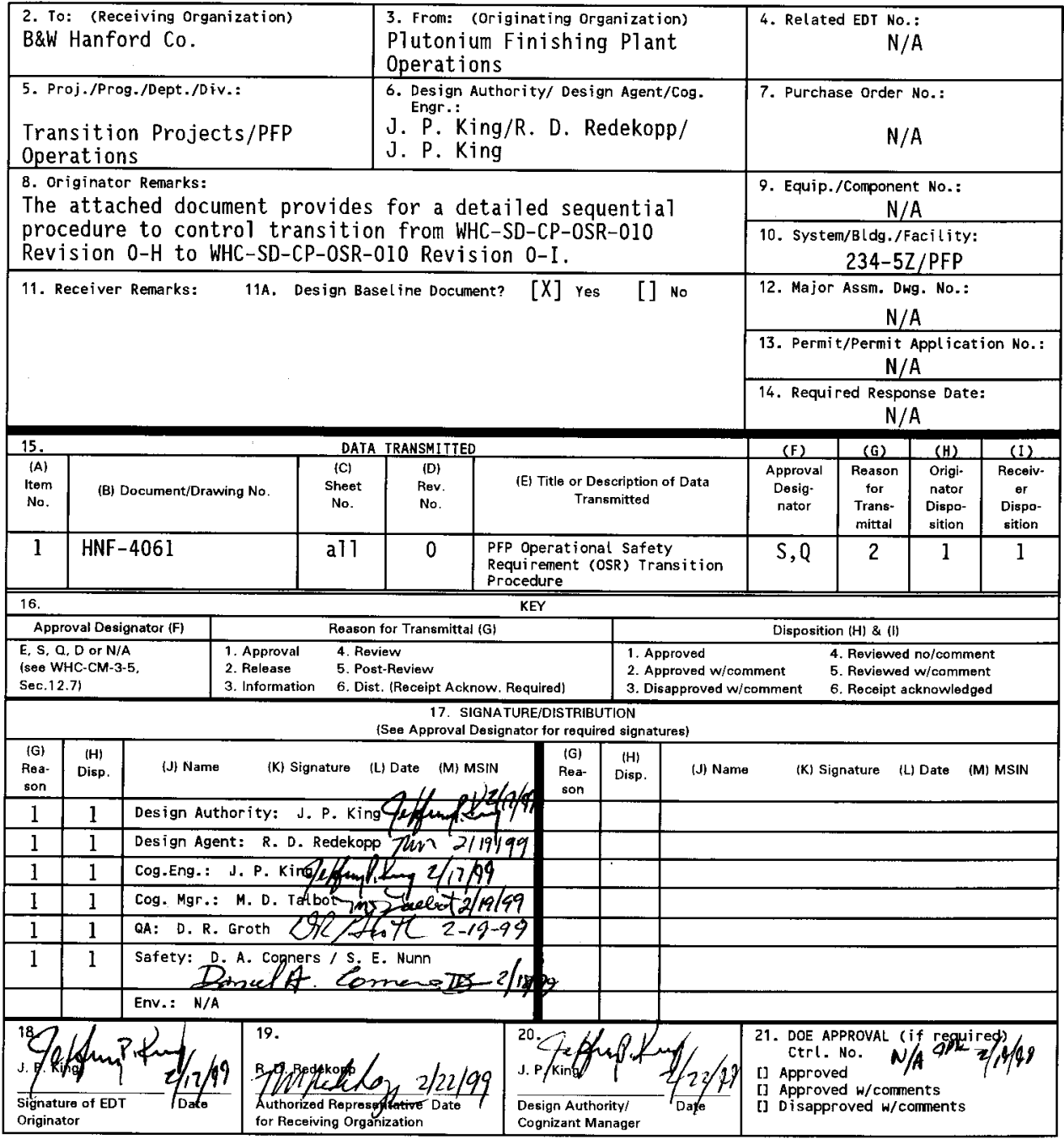




\section{PFP Operational Safety Requirement (OSR) Transition Procedure}

J. P. King

BWHC, Richland, WA 99352

U.S. Department of Energy Contract DE-AC06-96RL13200

$\begin{array}{lllll}\text { EDT/ECN: } & 626600 & \text { UC: } 507 & & \\ \text { Org Code: } & 15500 & \text { Charge Code: } & \text { CACN } 101418 \text { COA BB20 } \\ \text { B\&R Code: } & \text { EW7002000 } & \text { Total Pages: } 18 & \end{array}$

Key Words: Operational Safety Requirement Implementation, Limiting Condition for Operation, Implementation Plan

Abstract: This document provides for a detailed sequential procedure to control transition from WHC-SD-CP-0SR-010 Rev. O-H to WHC-SD-CP-0SR-010 Revision $0-I$.

TRADEMARK DISCLAIMER. Reference herein to any specific comercial product, process, or service by trade name, trademark, manufacturer, or otherwise, does not necessarily constitute or imply its endorsement, recommendation, or favoring by the United States Government or any agency thereof or its contractors or subcontractors.

Printed in the United States of America. To obtain copies of this document contact: Document Control Services, P.0. Box 950, Mailstop H6-08, Richland WA 99352, Phone (509) 372-2420; Fax (509) 376-4989.

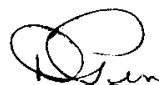

Release Approval
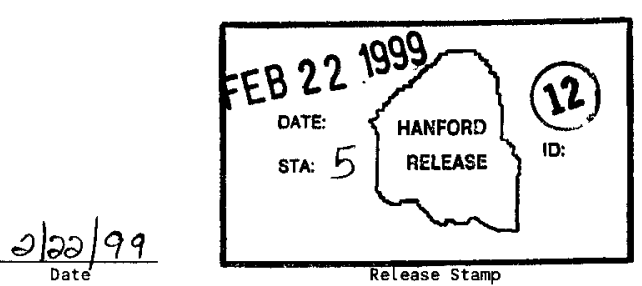
HNF-4061

PFP OPERATIONAL SAFETY REQUIREMENT (OSR) TRANSITION PROCEDURE

REVISION 0

IMPACT LEVEL

SQ 


\section{TABLE OF CONTENTS}

1.0 PURPOSE ....................... . . . 3

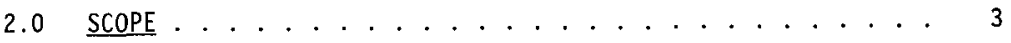

3.0 INTRODUCTION . . . . . . . . . . . . . . . . . . . 4

4.0 PREPARATION FOR NEW OSR IMPLEMENTATION . . . . . . . . . . . 6 4.1 DOCUMENT PREPARATION ................ 6

4.2 TRAINING ................. . . . 7

4.3 PLANT PREPARATION ................ . . . 8

4.4 ADMINISTRATIVE SYSTEM PREPARATION . . . . . . . . . . . 9

5.0 OSR APPROVAL . . . . . . . . . . . . . . . . . 9

6.0 OSR IMPLEMENTATION . . . . . . . . . . . . . . . . . . . . 9

6.1 AC IMPLEMENTATION . . . . . . . . . . . . . . . . . . . 9

6.2 LCO IMPLEMENTATION ................. . . . . 10

6.2.1 General Instructions . . . . . . . . . . . . . 10

6.2.2 Use of the 0SR Transition Matrix (Attachment B) 10

6.2.3 LCO Implementation Process . . . . . . . . . . 11

6.2.4 Obsolete SR Procedure Disposition . . . . . . . . . 13

6.2.5 OSR Revision Implementation Completion Sign off

6.3 TRANSITION PROCEDURE IMPLEMENTATION . . . . . . . . 13

7.0 REFERENCES .................... . . . . 14

ATTACHMENT A, DOCUMENTS REQUIRED FOR TRANSITION . . . . . . . . . A-1

ATTACHMENT B, OSR TRANSITION MATRIX . . . . . . . . . . . . B-1 
ReY. 0

PFP OPERAT IONAL SAFETY RECUIREMENT (OSR) TRANSITIOH PROCEDURE

\section{HNF-4061 Rev. 0 \\ PFP OPERATIONAL SAFETY REQUIREMENT (OSR) TRANSITION PROCEDURE}

1.0 PURPOSE

The purpose of this document is to provide a detailed sequential procedure to control the transition from the current WHC-SD-CPOSR-0IO Revision $0-H$ to WHC-SD-CP-OSR-010 Revision $0-I$. This plan provides a structure for the implementation of OSR Revision 0-I and ensures that compliance with the current OSR Revision is maintained until Revision $0-I$ is fully implemented.

\section{$2.0 \quad \underline{\text { SCOPE }}$}

This document applies to plant processes, policies and personnel during transition from the current OSR Revision $0-H$ to the revised OSR Revision $0-\mathrm{I}$.

Implementation of the OSR Revision 0-I will begin upon approval of Engineering Change Notice (ECN) 631097 by the Department of Energy Richland Operations office (DOE-RL) and approval and issuance of this implementation plan. 


\section{$3.0 \quad$ INTRODUCTION}

3.1 ECN 631097 to WHC-SD-CP-OSR-010 Revision 0-F was submitted to DOE RL for approval by Fluor Daniel Hanford by letter 9753265 Revision 1, dated April 23, 1997. The purpose of the ECN was to: a) clarify the interaction between OSR required MODES and planned maintenance, and b) clarify and refine requirements for operation of the plant criticality alarm system (CAS). DOE-RL subsequently issued letter 97TPD-099 and attached Safety Evaluation Report (SER) approving ECN 631097 as OSR Revision 0-G.

During the 1997 ECN 631097 implementation period, a readiness assessment finding against the CAS back up power batteries was made (CR-1-F-003). The finding established that before CAS batteries could be designated as an "emergency power supply" meeting the requirements of ANSI/ANS-8.3-1986 "Criticality Accident Alarm System" Section 4.5, they must pass the load testing requirements of ANSI/IEEE Std 450-1987 "IEEE Recommended Practice for Maintenance, Testing, and Replacement for Large Lead Storage Batteries for Generating Stations and Substations", Section 5. Load testing of the CAS batteries required procurement of an adequate load testing device, procurement of two extra sets of CAS batteries, and physically testing and installing nine battery sets. Testing and installation of load tested batteries for all criticality alarm panels (CAPs) was completed in August 1998.

During the extended implementation period, two additional changes to WHC-SD-CP-OSR-010 Revision $0-F$ were required in order to ensure continued compliance with Final Safety Analysis Report commitments. These changes were issued as a new Revision 0-G, and a Revision 0-H. Because ECN 631097 could no longer be issued as the previously approved OSR Revision $0-G$, it had to be resubmitted to DOE-RL as OSR Revision 0-I and is discussed in approval letter 99-TPD-021 dated February 4, 1999. 
3.2 The OSR Limiting Condition for Operation (LCO) changes wil1 be implemented over a period of four weeks in accordance with steps contained in this implementation plan commencing upon plan approval.

3.3 This procedure incorporates all elements of FSP-PFP-5-8 Plutonium Finishing Plant Administration Volume 2, Section 13.3 "Operational Safety Requirement Compliance" Paragraph 5.22 and will be used instead of FSP-PFP-5-8 Volume 2 Section 13.3 due to the complexity of the OSR change implementation steps. This procedure will outline the activities necessary to implement LCO changes approved in OSR Revision $0-I$ and track the progress using the OSR LCO Transition Matrix (Attachment B). Completion of each item will be verified and documented by a sign off by the Operations OSR Representative and the Operations Manager.

3.4 The PFP Operations Manager is the owner of this document and Operations will track the completion of each item.

3.5 The transition process consists of:

- Preparation

- WHC-SD-CP-0SR-010, Rev. 0-I, approval

- Revised LCO implementation

- Dispositioning of old compliance documents or procedures (if necessary).

3.6 The emphasis of the implementation is to ensure compliance to existing OSR LCO surveillance requirements (SRs) until implementation of OSR Revision $O-I$ is complete. Before the revised $L C O$ is implemented the surveillance requirements of the previous LCO revision will be verified as complete and compliance document status will be recorded.

\subsection{OSR TRANSITION MATRIX (ATTACHMENT B) DEVELOPMENT}

3.7.1 The matrix was developed by assembling a list of OSR Revision $0-I$ related policies, procedures, and maintenance work packages.

3.7.2 The matrix provides a listing of affected procedures and a summary of the major changes made to each. 


\subsection{PREPARATION FOR NEW OSR IMPLEMENTATION}

This section of the procedure provides a list of prerequisite activities to OSR Revision O-I implementation. The categories are document preparation, training, plant system preparation, and administrative implementation. Completion of this section is a prerequisite to completion of OSR Revision 0-I implementation. Steps $4.1,4.2$, and 4.3 may be performed in paralle1.

\subsection{DOCUMENT PREPARATION}

4.1.1 Attachment A presents the list of documents requiring modification or revision for OSR Revision 0-I implementation. Documents are listed by hierarchy, the first group being those required to start the implementation process, then those necessary to implement the LCOS.

4.1.2 To avoid delay in the implementation of the new OSR Revision the supporting documents will be approved, ready for the USQ screening process, and staged for issuance prior to OSR approval to the greatest extent possible.

4.1.3 Approval of these supporting documents will be based on ECN 631097 previously approved as OSR Revision 0-G.

4.1.4 Only the revision/modification number and issuance date of WHC-SD-CP-0SR-010, Revision 0-I has changed from when it was originally approved as OSR Revision $0-G$. Therefore, technical changes to supporting documents approved against ECN 631097 OSR Revision O-G should not be required. The documents will be examined before final release to verify that any OSR Revision references contained in them reference the re-approved OSR Revision D-I. 
4.1.5 Necessary changes to the supporting documents and data bases will be made using normal document control system described in FSP-PFP-5-8. PFP Operations wi11 sign Attachment $A$, based on input from the responsible individuals, when the document is prepared and ready to release in support WHC-SD-CP-OSR-010, Rev. 0-I implementation.

4.1.6 Verification of Document Preparation:

A71 Documents Required for Implementation 1 isted in Attachment $A$ are approved to the DOE approved version of WHC-SD-CP-OSR-010, Revision O-G (re-approved as OSR Revision 0-I). Documents originally approved to the previously approved but not released version of WHCSD-CP-OSR-010, Revision $0-G$, have been examined and changed before final release (if necessary) to reference the re-approved OSR Revision $0-I$.

Manager, PFP Operations

\subsection{TRAINING}

Operations Shift Managers (Building Emergency Directors), operations Engineers (OES), and CAS cognizant engineers have been trained on WHC-SD-CP-OSR-010, Revision 0-I. The plant staff is ready to implement the revised OSR LCOS.

Manager, PFP Operations $1 /$ Date




\subsection{PLANT PREPARATION}

\subsubsection{Criticality Alarm System modifications/testing} necessary to support OSR implementation have been performed and are listed below:

\begin{tabular}{|c|c|c|c|}
\hline $\begin{array}{l}\mathrm{LCO} \\
3.1 .2 \\
\end{array}$ & Item Description & $\begin{array}{l}\text { JCS Work } \\
\text { Package No. }\end{array}$ & $\begin{array}{l}\text { Completion } \\
\text { Date }\end{array}$ \\
\hline & $\begin{array}{l}\text { Load test and replace CAP Z-1 } \\
\text { batteries }\end{array}$ & $2 Z-98-01285 / P$ & $8 / 17 / 98$ \\
\hline & $\begin{array}{l}\text { Load test and replace CAP Z-2 } \\
\text { batteries }\end{array}$ & $2 Z-98-01283 / P$ & $8 / 3 / 98$ \\
\hline & $\begin{array}{l}\text { Load test and replace CAP Z-3 } \\
\text { batteries }\end{array}$ & $2 Z-98-01140 / P$ & $7 / 18 / 98$ \\
\hline & $\begin{array}{l}\text { Load test and replace CAP Z-4 } \\
\text { batteries }\end{array}$ & $2 Z-98-00301 / \mathrm{S}$ & $7 / 7 / 98$ \\
\hline & $\begin{array}{l}\text { Load test and replace CAP Z-5 } \\
\text { batteries }\end{array}$ & $2 Z-97-01241 / B$ & $3 / 11 / 98$ \\
\hline . & $\begin{array}{l}\text { Load test and replace CAP Z-6 } \\
\text { batteries }\end{array}$ & $2 Z-97-01241 / B$ & $3 / 11 / 98$ \\
\hline & $\begin{array}{l}\text { Load test and replace CAP Z-7 } \\
\text { batteries }\end{array}$ & $2 Z-98-00109 / W$ & $1 / 15 / 98$ \\
\hline & $\begin{array}{l}\text { Load test and replace CAP Z-8 } \\
\text { batteries }\end{array}$ & $2 Z-97-02661 / W$ & $4 / 22 / 98$ \\
\hline & $\begin{array}{l}\text { Load test and replace CAP Z-9 } \\
\text { batteries }\end{array}$ & $2 Z-98-00737 / W$ & $6 / 3 / 98$ \\
\hline
\end{tabular}

4.3.2 Periodic Maintenance and Surveillance (PM/S) activities have been created and entered into the PFP Job Control System (JCS) to schedule and reperform CAP battery load tests and replacements.

(NOTE: CAP batteries are required to be load tested within two years of new installation and then every five years thereafter while in service, or any time they fail the monthly/quarterly ZSE surveillance requirement inspection). PM/S activities reflect this schedule.

Manager, Maintenance Administration and Support Date




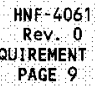

\subsection{ADMINISTRATIVE SYSTEM PREPARATION}

4.4.1 PFP Maintenance Administration and Support is prepared to recal1/schedule revised OSR LCO 3.1 .2 surveillance requirements using the JCS PM/S module as described by FSP-PFP-5-8, Section 13.1, OSR Preventive Maintenance and Surveillance Recall System.

Manager, Maintenance Administration and Support Date

5.0 OSR APPROVAL

5.1 WHC-SD-CP-OSR-010, PFP OPERATIONAL SAFETY REQUIREMENTS, Revision $0-I$ has received approval from DOE. OSR transition can start for affected $A C$ and LCOS. (attach copy of DOE Letter 98-TPD-028 as documentation)

5.2 Preparations for OSR Implementation (per Section 4.0) are complete. The process for implementation of the WHC-SD-CPOSR-010, Revision 0-I can begin. The preparations for implementation as identified in Sections $4.1,4.2,4.3$, and 4.4 have been completed.

Manager, PFP Operations

\subsection{OSR IMPLEMENTATION}

6.1 ADMINISTRATIVE CONTROL (AC) IMPLEMENTATION $A$ matrix showing the $A C$ requirement and the compliance documents is presented in Section 13.3 of WHC-CM-5-8. The revision to $A C 5.5 .3$ will be considered to be in effect upon completion of this implementation plan. 


\subsection{LCO IMPLEMENTATION}

\subsubsection{Genera1 Instructions}

A. The surveillance requirements (SR) of WHC-SD-CPOSR-010, Revision $0-H$ LCO 3.1.2, are verified as being met and documented through the performance of specific surveillance procedures as presented in FSP-PFP-5-8, Section 13.3 Appendices $A$ and F.

B. Each revised LCO SR will be performed and implemented during the next performance scheduled by the preventative maintenance and recall system.

\subsubsection{Use of the OSR Transition Matrix (Attachment B)}

A. The purpose of the transition matrix is to demonstrate during the transition period that compliance to approved OSR LCOS is maintained. To achieve this, the transition matrix will present information showing that existing OSR surveillances have been performed on schedule and that new surveillances are performed before declaring the revised OSR LCO in effect, thus demonstrating compliance before and after implementation of the LCO.

B. Column 3 and Column 4 will show the last performance date and the due date of the existing surveillance procedure. This data must be obtained from the recall organization and is filled in by PFP Operations.

C. Column 5 shows the procedures that are used to verify compliance with the revised LCO. 
D. Column 6 is a signature block to verify that the procedure in column 5 has been performed and establishes compliance with the revised LCO. This block should be signed by PFP Operations based on input from Maintenance Administration and Support.

E. Column 7 is the signature block that will be signed when the procedure 7 isted in column 2 has been dispositioned. PFP Operations will sign this block when the processing of the change request has been completed and the appropriate data base has been updated.

F. Column 8 is the signature block for the Manager of PFP Operations, a second check verifying that all actions of the line item have been completed satisfactorily.

\subsubsection{LCO Implementation Process}

A. Al1 documents 1 isted in Attachment $A$ that are required for the $L C O$ being implemented are approved to the DOE approved version of WHC-SDCP-OSR-010, Revision 0-I.

B. Initiate any Plant Changes that need to be performed for the LCO being implemented. They have been identified in Section 4.3 and the Work Packages are complete.

C. Obtain "last done" and "next due" dates for each of the existing surveillances and record in Column 3 and 4 of the Transition Matrix. 
D. Verify that each current surveillance is not past due.

1. If it is the surveillance must be performed.

2. If the current surveillance becomes due before the new LCO is implemented the current surveillance will have to be performed.

E. The Transition Matrix identifies the new surveillance procedures that verify compliance with the revised LCO. For each new surveillance procedure identified by the matrix, PFP operations will perform the following:

1. Verify the procedure is field validated and approved to WHC-SD-CP-OSR-010 Revision 0 - I based on approval signature of the Document Acceptance Form (DAF) by the Approval Authority.

2. Contact Maintenance Administration and Support and verify the component or procedure recall activities are prepared, validated by the cognizant engineer, and are ready for recall system input and use.

3. Verify revised surveillance procedures have been scheduled and performed.

4. Complete this process for each revised surveillance procedure. 


\subsubsection{Obsolete SR Procedure Disposition}

Any procedure identified as a surveillance for the old OSR LCO revision but not applicable to the revised OSR LCO needs to be dispositioned. Responsibility for dispositioning the procedure belongs with the related system Cognizant Engineer. PFP Operations will sign Attachment B when the disposition is complete based on input from the Cognizant Engineer.

\subsubsection{OSR Revision Implementation Completion Sign Off}

Verify that changes 1 isted in Section 4 related to the LCO being implemented are complete. PFP Operations will sign on the implementation status signature line below based on input from the responsible individuals and review of completed work packages. PFP Operations will issue appropriate plant operating instructions notifying affected $p l$ ant operating personnel that OSR implementation actions have been completed and that the plant is to be operated under the revised LCOS and ACs.

PFP Operations

The PFP Operations Manager will then sign, signifying OSR revision implementation is complete.

Manager, PFP Operations Date

\subsection{TRANSITION PROCEDURE IMPLEMENTATION}

The master copy of this Transition Procedure will be printed on yellow paper and be maintained 


\subsection{REFERENCES}

7.1 WHC-SD-CP-OSR-010, Rev, 0-I, PLUTONIUM FINISHING PLANT OPERATIONAL SAFETY REQUIREMENTS

7.2 FSP-PFP-5-8, PFP ADMINISTRATION MANUAL Volumes $1 \& 2$.

7.3 Department of Energy, Richland Operations Office, Letter 97TPD-099, "Contract Number: DE-AC-06-96RL13200 - Approval of Revision $0-G$ to the Operational Safety Requirements (OSR) for the Plutonium Finishing Plant (PFP)", Dated 7/11/97.

7.4 Fluor Daniel Hanford, Inc., Letter FDH-9756240 R2, "Contract Number: DE-AC-06-96RL13200 - Approval of Revision 0-G to the 0perational Safety Requirements (OSR) for the Plutonium Finishing Plant (PFP)", Dated 10/29/98.

7.5 Department of Energy, Richland Operations Office, Letter 99TPD-028, "Contract No. DE-AC-06-96RL13200 - Approval of Revision to the Operational Safety Requirements (OSR) for the Plutonium Finishing Plant (PFP)", Dated 2/4/99.

7.6 Department of Energy, Richland Operations Office, Letter 97TPD-162, "Contract Number: DE-AC-06-96RL13200 - Plutonium Finishing Plant (PFP) Fissile Material Movement Readiness Assessment (RA)", Dated 9/5/97. 


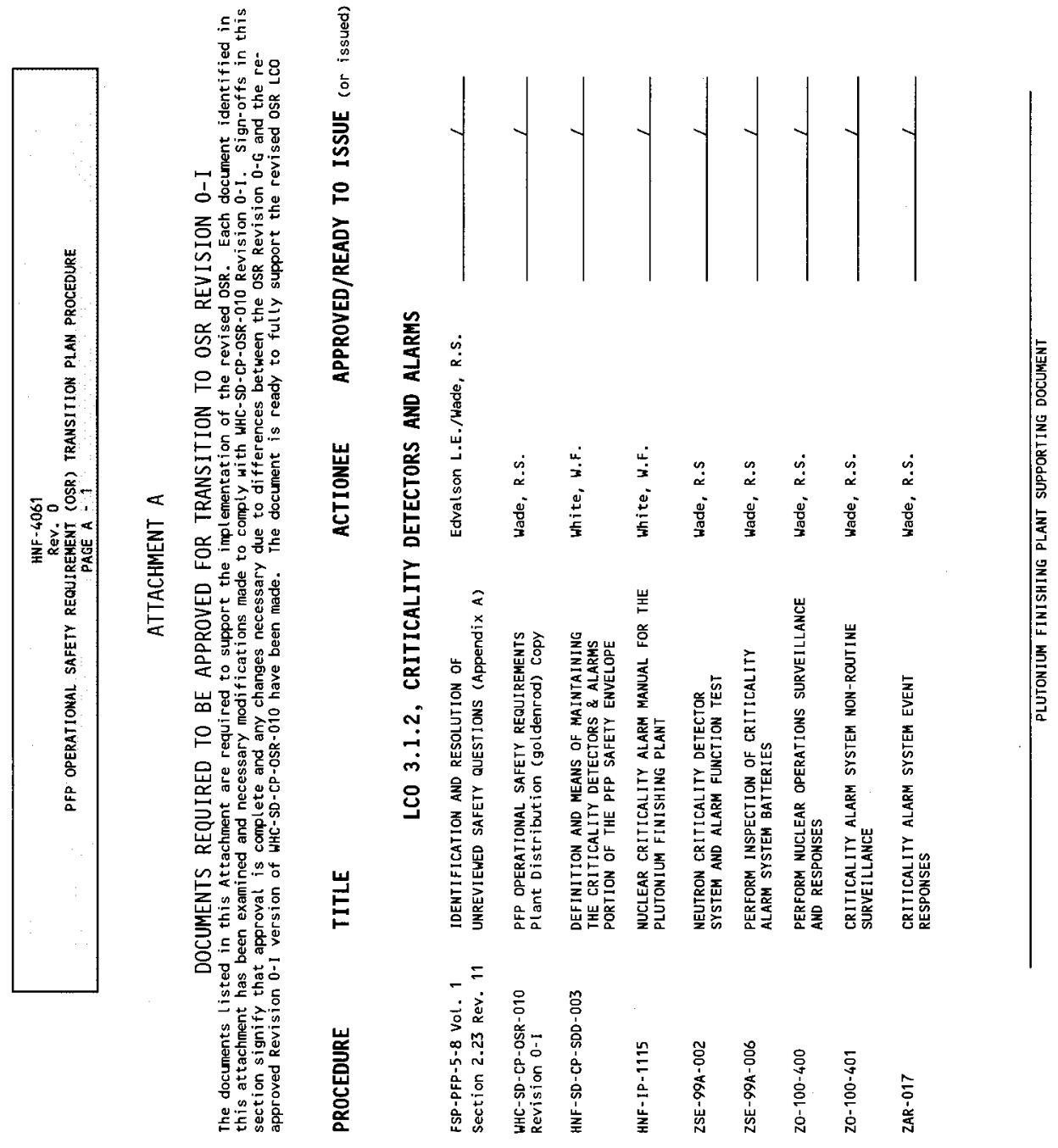




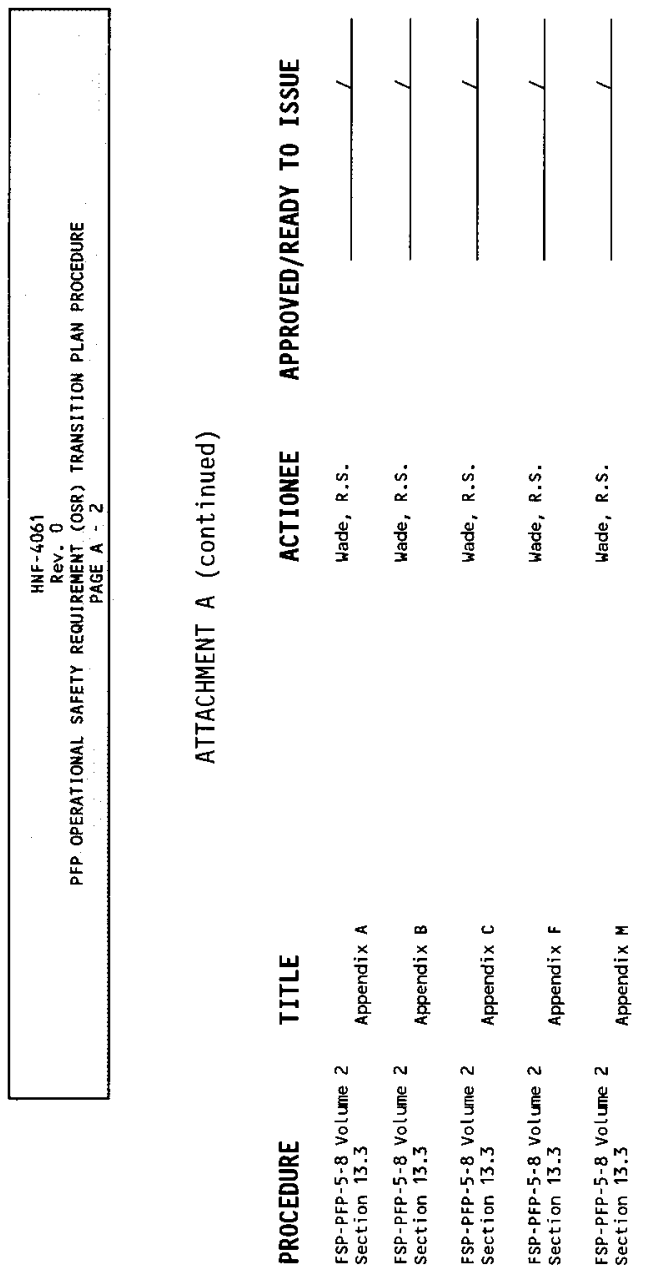




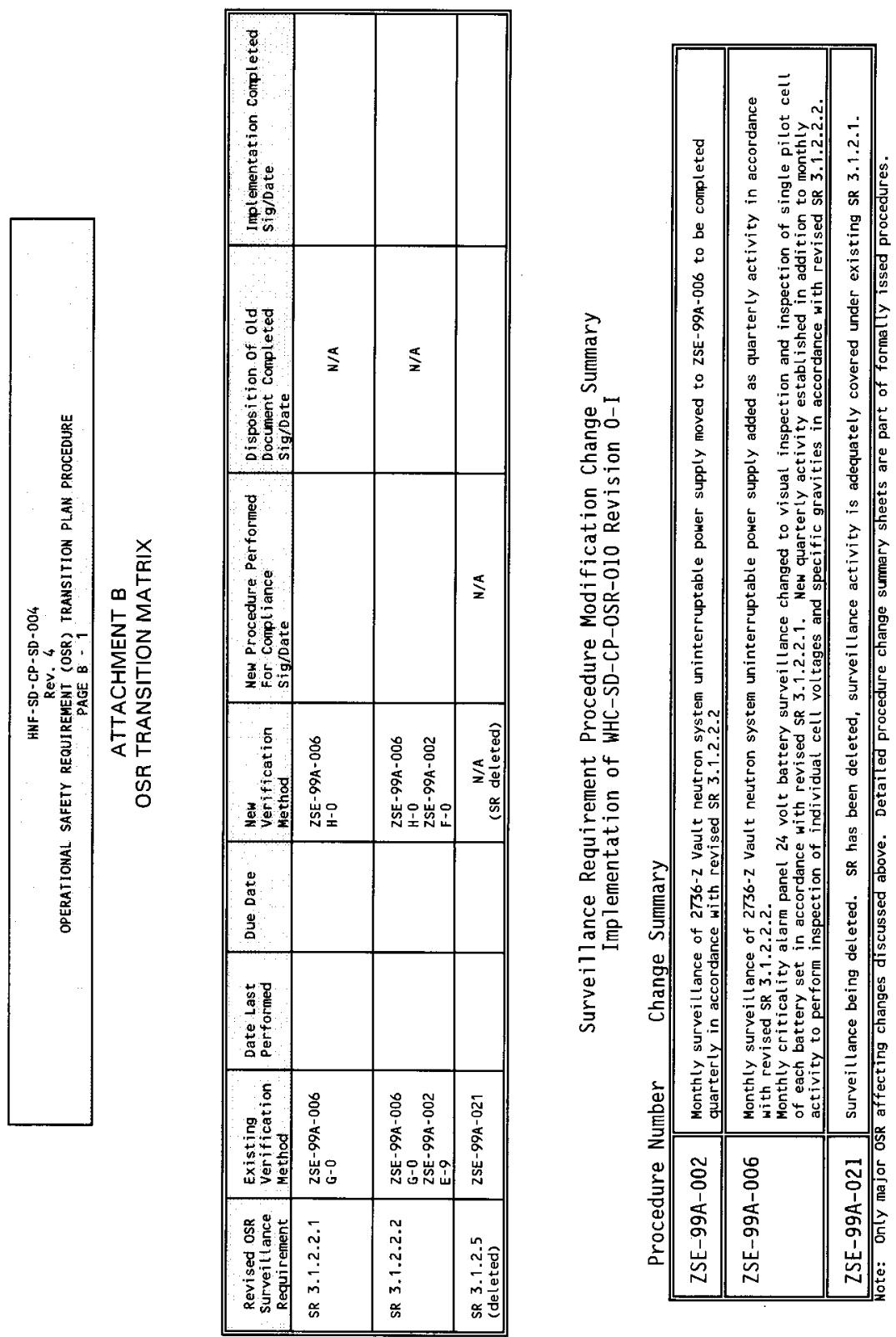




\section{DISTRIBUTION SHEET}

\begin{tabular}{|c|c|c|c|c|c|c|}
\hline \multirow{2}{*}{$\begin{array}{l}\text { To } \\
\text { Distribution }\end{array}$} & \multirow{2}{*}{\multicolumn{4}{|c|}{$\begin{array}{l}\text { From } \\
\text { J. P. King }\end{array}$}} & \multicolumn{2}{|c|}{ Page 1 of 1} \\
\hline & & & & & \multicolumn{2}{|c|}{ Date $2 / 22 / 99$} \\
\hline \multirow{2}{*}{\multicolumn{5}{|c|}{$\begin{array}{l}\text { Project Title/Work Order } \\
\text { HNF-4061 PFP Operational Safety Requirement (OSR) } \\
\text { Transition Procedure }\end{array}$}} & \multirow{2}{*}{\multicolumn{2}{|c|}{$\begin{array}{lll}\text { EDT } & \text { No. } & 626600 \\
\text { ECN No. } & \text { N/A }\end{array}$}} \\
\hline & & & & & & \\
\hline Name & & MSIN & $\begin{array}{c}\text { Text } \\
\text { With } \\
\text { All } \\
\text { Attach } \\
\text {. }\end{array}$ & $\begin{array}{l}\text { Text } \\
\text { Only }\end{array}$ & $\begin{array}{c}\text { Attach. } \\
/ \\
\text { Appendi } \\
x \\
\text { Only }\end{array}$ & $\begin{array}{c}\mathrm{EDT} / \mathrm{ECN} \\
\text { Only }\end{array}$ \\
\hline
\end{tabular}

K. K. Chitkara

D. A. Conners

D. E. Groth

J. P. King

J. J. McCracken

L5-65 X

T5-11 $\mathrm{X}$

T4-15 X

T5-51 $\mathrm{X}$

R. $3-79 \quad X$

A. L. Ramble

T5 -54

R. D. Redekopp

P. E. Roege

T5-15

T5 57

M. D. Talbot

T5-15

Central Eiles

B1-07

DOE/RL Reading Room

$\mathrm{H} 2-53$

$\mathrm{X}$

$\mathrm{X}$

$\mathrm{X}$

$\mathrm{X}$ 